\title{
Liquid Metal Embrittlement in Resistance Spot Welding (Fourth Report)
}

\author{
- Evaluation of Liquid Metal Embrittlement Using Resistance Spot Welding FEA Simulation - \\ Hideki Ueda $^{\text {1) }}$ Seiji Furusako $^{2)}$ Tohru Okada $^{2)}$ Shota Kikuchi $^{3)}$ \\ 1) Nippon Steel Corporation, Steel Research Laboratories \\ 1-8 Fuso-cho, Amagasaki, Hyogo, 660-0891, Japan \\ 2) Nippon Steel Corporation, Steel Research Laboratories \\ 20-1 Shintomi, Futtsu, Chiba, 293-8511, Japan \\ 3) Nippon Steel Corporation, Nagoya $R \& D$ Laboratories \\ 5-3 Tokai-cho, Tokai, Aichi, 476-8686, Japan
}

Received on March 14,2020

\begin{abstract}
This paper describes the development of the finite element (FE) analysis system for comprehensive evaluation of the phenomena occurring during resistance spot welding. The framework underlying this system is FE calculation based on an incrementally coupled electrical-thermal-mechanical simulation procedure. In recent years, evaluation of stress in the spot welding process has been important for elucidating the mechanism of liquid metal embrittlement (LME) crack formation. This analytic system is applied to evaluating the influence of clearance between steel sheets and electrodes on residual stress in the spot welded zone.
\end{abstract}

KEY WORDS: Materials, Iron and Steel materials, Welding / Spot welding, Liquid Metal Embrittlement, FEM [D3]

\section{Introduction}

Resistance spot welding (hereinafter referred to as "spot welding") is widely used as a jointing method in the process of assembling automotive bodies and parts. At the same time, high strength steel sheets (hereinafter referred to as "HSS") are widely used in many kinds of automotive component, in order to reduce body weight and improve crashworthiness.

In recent years, liquid metal embrittlement (hereinafter referred to as "LME") cracks have been reported in spot welds of ultra-HSS with zinc-based plating, and it is thought that these cracks occur especially in the case conditions where disturbances occur, such as the clearance between the electrode and the steel sheet. We have developed a method for simulating resistance spot welding based on incrementally coupled electrical-thermalmechanical fields using finite element analysis (hereinafter referred to as "FEA"), and have been working on establishing basic technology to accurately predict nugget growth and spatter evolution under any welding conditions and steel sheet combination, including coated plates ${ }^{(1)(2)(3)}$. In addition, this technology has verified the accuracy of the heating and cooling processes, and has been confirmed as effective in evaluating residual stress ${ }^{(4)}$. In this report, using the analysis simulation method mentioned above, we study the influence of clearance on the tensile stress in corona bonds during the spot welding process to elucidate the mechanism of LME crack initiation, and evaluate the transition of stress and plastic strain due to cooling by electrode-hold contact cooling, electrode release and air cooling.

\section{Overview of the Resistance Spot Welding FEA Simulation}

2.1. Overview of the spot welding process
Figure 1 shows an overview of the spot welding process. The spot welding process consists of: (1) the welding step, in which the electrodes are energized while pressing against the workpieces; (2) the holding step, where the electrodes hold the workpieces in place under pressure; and (3) the cooling step, in which the electrodes are released and the weld zone cools to ambient temperature.

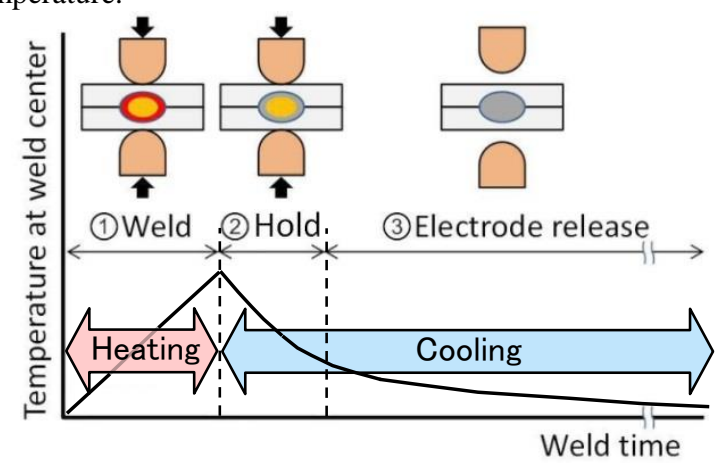

Fig. 1 Schematic of temperature transition of spot welds.

2.2. Overview of the FEA method based on the incrementally coupled electrical-thermal-mechanical simulation procedure

Figure 2 shows a schematic illustration of the incrementally coupled electrical-thermal-mechanical analysis procedure. In order to model the spot welding process by numerical analysis simulation, in the heating process(1), the basic flow involves alternately repeating the coupled electrical-thermal (hereinafter referred to as the "E-T analysis") analysis and the coupled thermal-mechanical analysis (hereinafter referred to as the "T-M analysis") at appropriate small intervals. In the cooling process((2) and (3)), T-M analysis is applied. These simulations include the transformations and phase changes associated with temperature changes, and apply temperature-dependent material 
property data (thermal physical properties, electrical resistivity, flow curves) collected from various steel sheets. This simulation system is composed of many user subroutines as well as our own peripheral programs based on Abaqus, a suite of general-purpose FEM analysis codes.

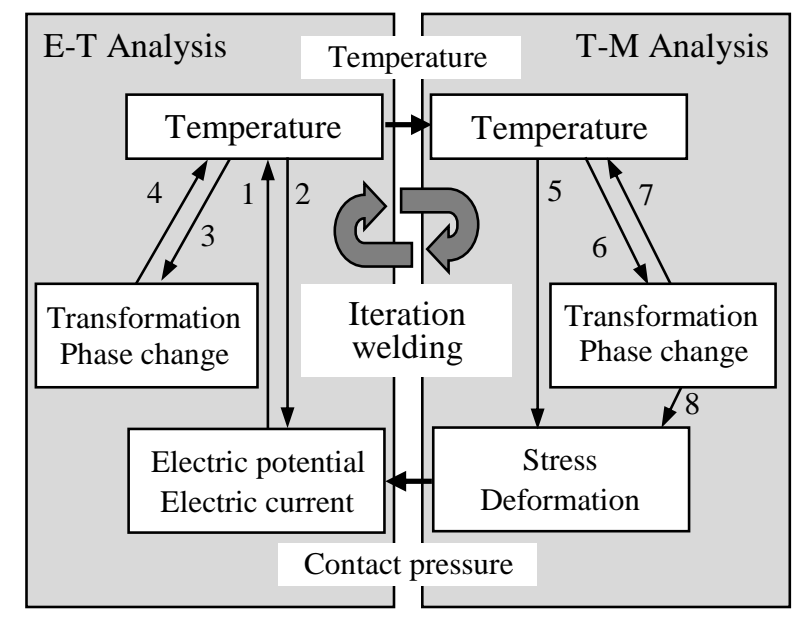

1: Joule heat 2: Temperature-dependent material properties

3, 6: Phase change and transformation 4, 7: Latent heat

5: Temperature-dependent material properties and thermal expansion

8: Microstructure-dependent material properties,

transformation expansion, and transformation plasticity

Fig. 2 Schematic illustration of the incrementally coupled electrical-thermal-mechanical analysis procedure.

\subsection{Accuracy verification}

\subsubsection{Overview}

In the initial phase of the heating step of spot welding, heat due to plate-plate resistance and plates-electrodes resistance is dominant, and accurate estimation is extremely important for ensuring simulation accuracy. The FEA model in this study can be used to obtain an appropriate contact resistance value, considering the effects of contact pressure and current diameter changes that occur over time. As a result, the resistance heating value at the interfaces is properly calculated, and the accuracy of predicting nugget growth improves. In addition, the cooling process includes changes in the structure fraction due to phase transformation. These are estimated using the formula proposed by Li et al. ${ }^{(5)}$, which predicts transformations based on chemical composition and austenite grain size. For the martensitic transformation, the formula proposed by Koistinen et al. ${ }^{(6)}$ is used. Although the details of accuracy verification have already been reported in the previous report ${ }^{(4)}$, this section briefly describes the verification results.

\subsubsection{Accuracy verification for the heating process}

To verify the accuracy of predicting nugget growth, we compared the analysis results with the experimental results of spot welding 980-MPa hot-dip galvannealed steel sheet (thickness: 1.6 $\mathrm{mm}$ ). The welding conditions were an electrode force of $3.43 \mathrm{kN}$, a welding time of 20 cycles $(60 \mathrm{~Hz})$, and the welding current was set on the basis of a target nugget diameter of $5.8 \mathrm{~mm}$, with 0.5 $\mathrm{kA}$ intervals before and after that. In the welding experiment, a two-dimensional axisymmetric model was used for the analysis because the specimen is not affected by the shape.

Figure 3 shows calculated results of the basis welding current, showing the growth of welding nuggets until the completion of electrical heating and the distribution of liquid phases at the completion of 20 cycles. Nugget diameter is in the range of a liquid phase ratio of 0.8 or more. Figure 4 shows relationships between welding current and nugget diameter (electrode force $=3.43 \mathrm{kN}$ ). The calculated results show good agreement with experimental results of the nugget diameter size, including judgment of sputter.

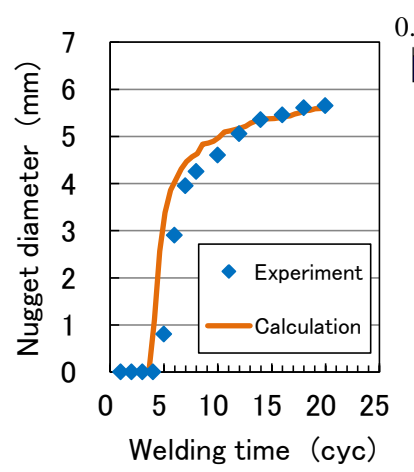

(a) Growth of welding nugget.
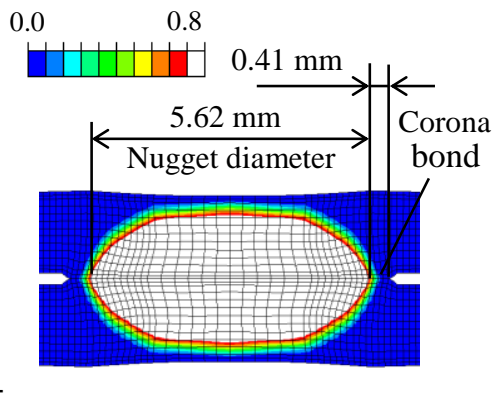

(b) Distribution of liquid phase ratio.
Fig. 3 Calculated result of basis welding current.

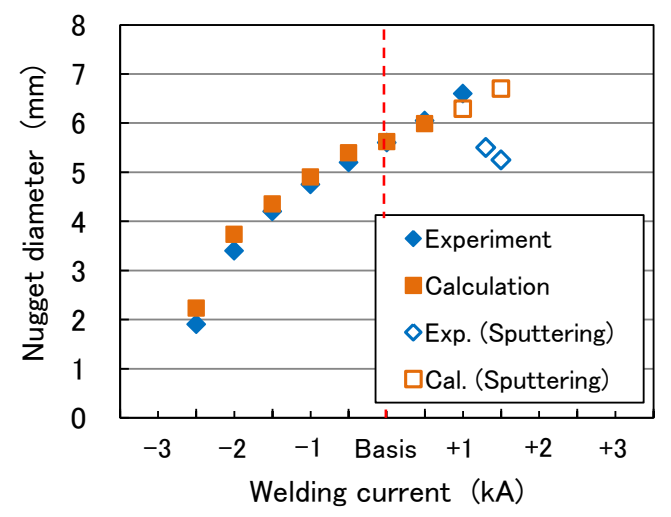

Fig. 4 Relationships between welding current and nugget diameter $($ Force $=3.43 \mathrm{kN}$ )

\subsubsection{Accuracy verification for the cooling process}

In general, the constraint and boundary conditions of the analysis model affect the stress during the cooling process. Therefore, in this section, we applied three-dimensional models to all calculations, including the current heating process. The evaluation specimens comprised a combination of 590-MPa steel sheet (sheet thickness $\mathrm{t}=1.6 \mathrm{~mm}$ ) and welding conditions set for a target nugget diameter of $5.6 \mathrm{~mm}$. The boundary condition was that steel sheet ends were free and the lower electrode was fixed. The heat transfer conditions during cooling were set to an ambient temperature of $20^{\circ} \mathrm{C}$ and a general air-cooling heat transfer coefficient between steel sheets and the atmosphere. The contact heat transfer condition for rapid cooling was set between steel sheets and electrodes. The evaluation specimens (steel sheets), welding conditions, and boundary conditions used in the experiment were the same as those used in the calculation.

First, to verify the analytic accuracy of the temperature transition in the cooling process, we compared calculated results with temperature measurement results. In the measurement tests, we used thermocouples (platinum-rhodium alloy material $\phi 0.1$ $\mathrm{mm})$ set in the groove of the test specimens to measure the temperature a certain distance from the weld center. Because we were evaluating differences in temperature transitions due to holding time, the test was performed twice for each of 5 and 40 holding cycles. Figure 5 shows temperature transitions during the cooling process, and it can be seen that the calculated results correspond to the measured test results. 
Vol.11, No.3(2020)

Next, we used the resistance spot welding FEA Simulation to compare the measured hardness distribution around the weld zone after the cooling process with the calculated results for the martensite volume fraction. Figure 6 shows a comparison between the measured Vickers hardness HV (1 kgf) results and the calculated results for the martensite volume fraction. The calculated results showed good agreement with measured test results.

Finally, we used the resistance spot welding FEA Simulation to compare the $\mathrm{X}$-ray stress measurement results with the calculated results for residual stress. Using the Rigaku X-ray stress measurement system PSPC-RSF ( $\sin ^{2} \phi$ method), the stresses were measured on the outer surface (electrode contact) of each spot welded zone. The measurement areas were $\phi 0.5 \mathrm{~mm}$. The stresses in the radial direction of the weld nugget were measured for two specimens manufactured under the same welding conditions. Figure 7 shows a comparison between the measured results and the calculated results for stresses in the radial direction, with the calculated results corresponding to the measured test results, indicating a general similarity between them.

As described above, it was confirmed that all of the calculated results in the heating process and the cooling process corresponded to the welding experimental and actually measured results.
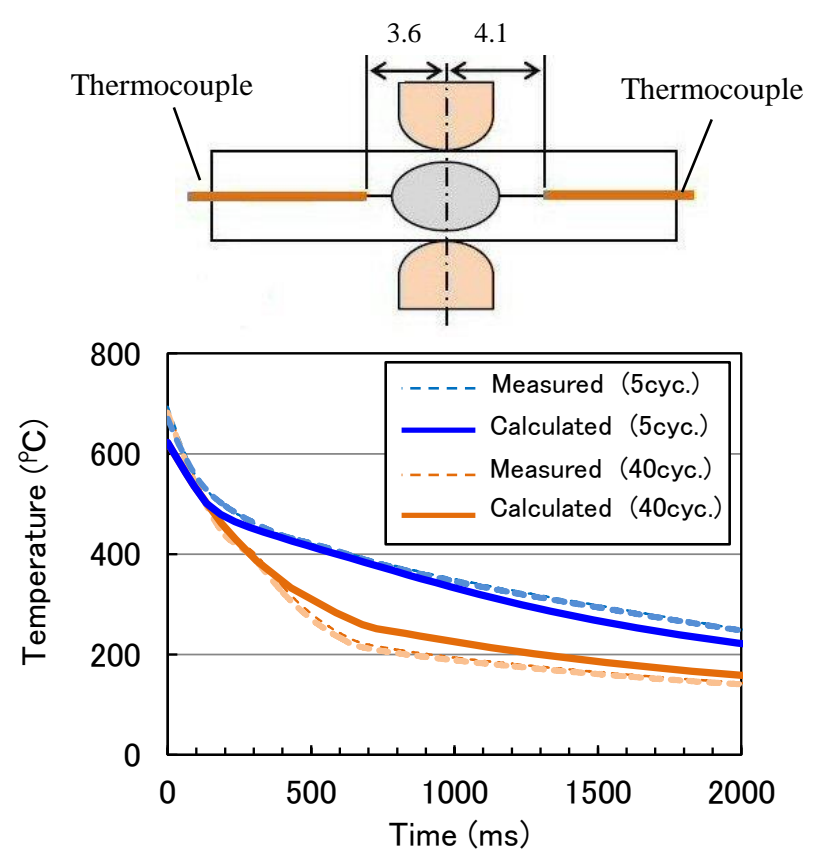

(a) $3.6 \mathrm{~mm}$ from nugget center.

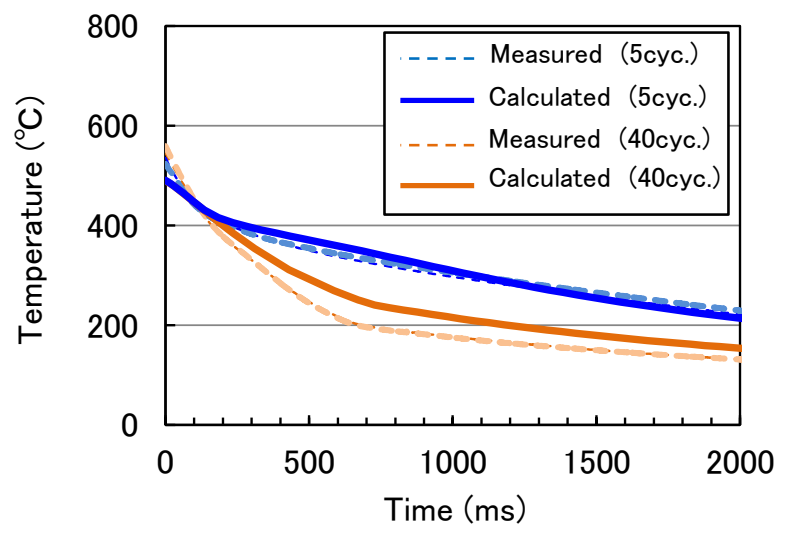

(b) $4.1 \mathrm{~mm}$ from nugget center.

Fig.5 Transition of temperature in cooling process.

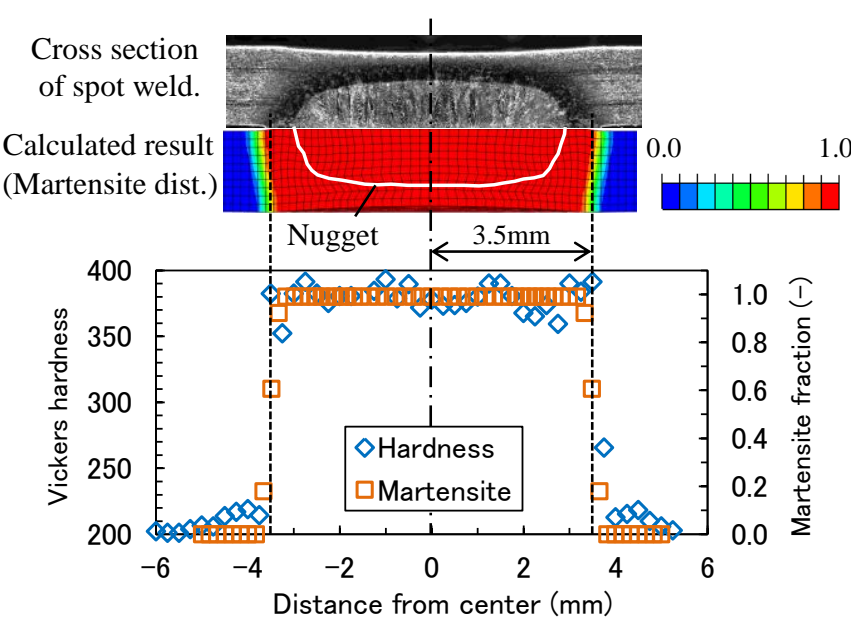

Fig. 6 Hardness distribution and quench zone.

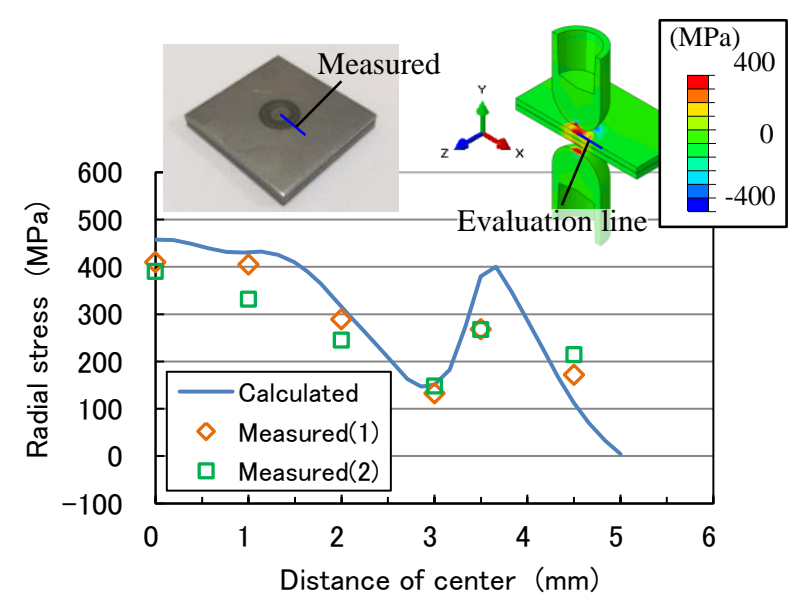

Fig. 7 Distribution of radial residual stress.

\section{Examination of LME cracking mechanism in corona bonds}

\subsection{Spot welding experiment}

In this chapter, we discuss the influence of clearance on LME cracking in corona bonds. The evaluated sheet combinations were made of $980-\mathrm{MPa}$ hot-dip galvannealed steel sheet measuring $50 \times 70 \times 1.6 \mathrm{~mm}$ each. Figure 8 shows a schematic diagram of the welding experiment with the clearance. The clearance was set by fixing the lower electrode and adjusting the spacer height. The welding conditions were an electrode force of $3.92 \mathrm{kN}$, a welding time of 17 cycles $(50 \mathrm{~Hz})$, and the welding current of $6.5 \mathrm{kA}$.

Figure 9 shows cross-sectional photographs of welding experimental results. When the clearance was set to $0.3 \mathrm{~mm}$ or 0.5 $\mathrm{mm}$, cracks initiated in corona bonds. Furthermore, under the condition that the clearance was expanded up to $1.0 \mathrm{~mm}$, the nugget figure was different from the other cases because of the large plastic deformation between the steel sheets by the electrode force and deep indentation on the lower electrode side. And this condition initiated no cracks. This suggests that the factor of the suppression of crack initiation was the compressive plastic strain in corona bonds. Therefore, in the case of this sheet combination, the clearance size that caused LME cracking was $0.3 \mathrm{~mm}$ to 0.5 $\mathrm{mm}$. 
Vol.11, No.3(2020)

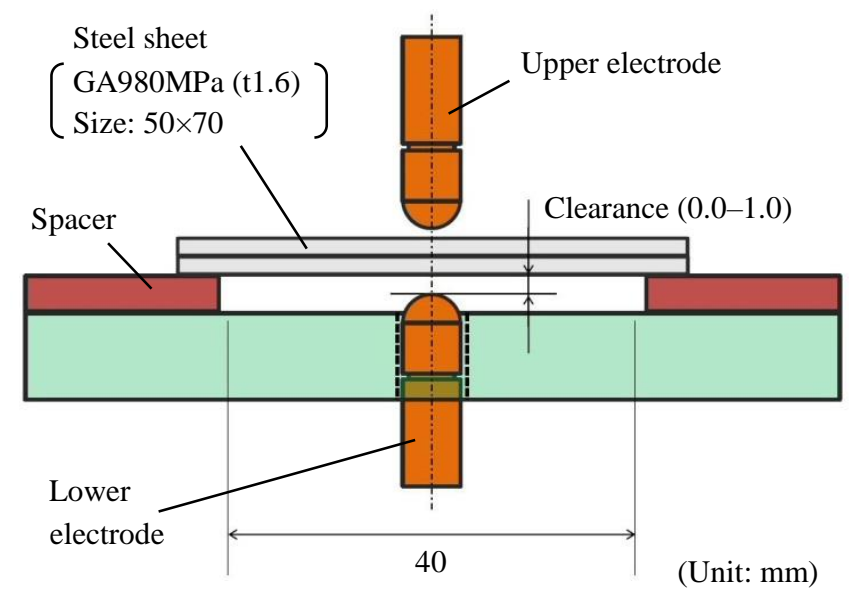

Fig.8 Experiment condition of spot welding with clearance.

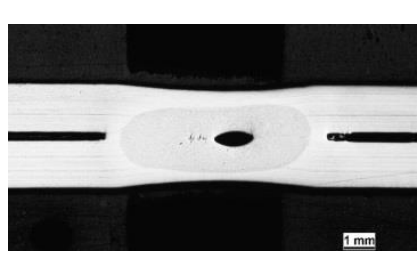

(a) $\mathrm{CL}=0.0 \mathrm{~mm}$

(Nugget diameter $=6.3 \mathrm{~mm}$ )

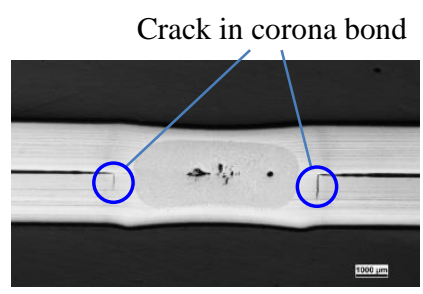

(c) $\mathrm{CL}=0.5 \mathrm{~mm}$

(Nugget diameter $=5.6 \mathrm{~mm}$ )

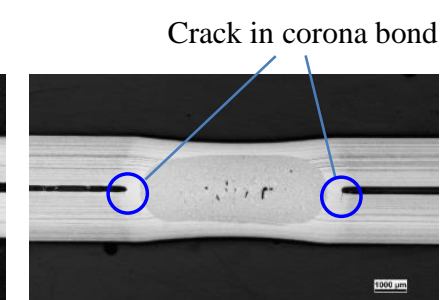

(b) $\mathrm{CL}=0.3 \mathrm{~mm}$

(Nugget diameter $=6.2 \mathrm{~mm}$ )

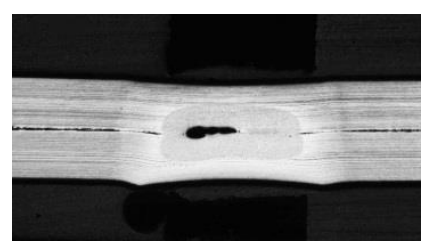

(d) $\mathrm{CL}=1.0 \mathrm{~mm}$

(Nugget diameter $=4.6 \mathrm{~mm})$
Fig. 9 Cross-sections of spot weld.

\subsection{FEA model}

Using this analysis system, we evaluated the influence of the clearance between the steel sheet and electrode on the stress and plastic strain in corona bonds during spot welding to elucidate the mechanism of LME crack initiation. Figure 10 shows the FE analysis model for spot welding. FEA Modeling is performed with using 1/4 symmetrical shapes divided into hexahedral mesh elements. Because of the symmetry in the $\mathrm{x}$-axis direction and the z-axis direction, the symmetry plane was set on each inner surface. As in the welding experiment, the lower electrode was fixed, and the conditions for no clearance and $0.3 \mathrm{~mm}, 0.5 \mathrm{~mm}$, and $1.0 \mathrm{~mm}$ clearance were examined. Since steel sheet ends in the x-axis direction were supported by the spacer, boundary conditions at the end of the steel sheet were set so that the $\mathrm{x}$-axis direction and rotation around the $\mathrm{z}$-axis were free on the inner surface side. The welding conditions were adjusted to produce a target nugget diameter of $5.0 \mathrm{~mm}$, which corresponds to the experimental results. Temperature-dependent thermal physical properties, electrical resistivity, and flow curves collected from evaluated steel sheets were applied as material property data.

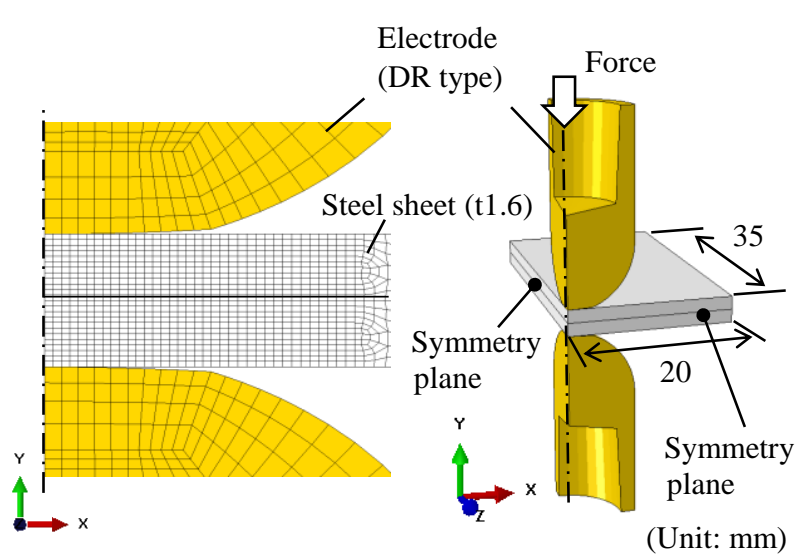

(a) Steel sheet combination without clearance.

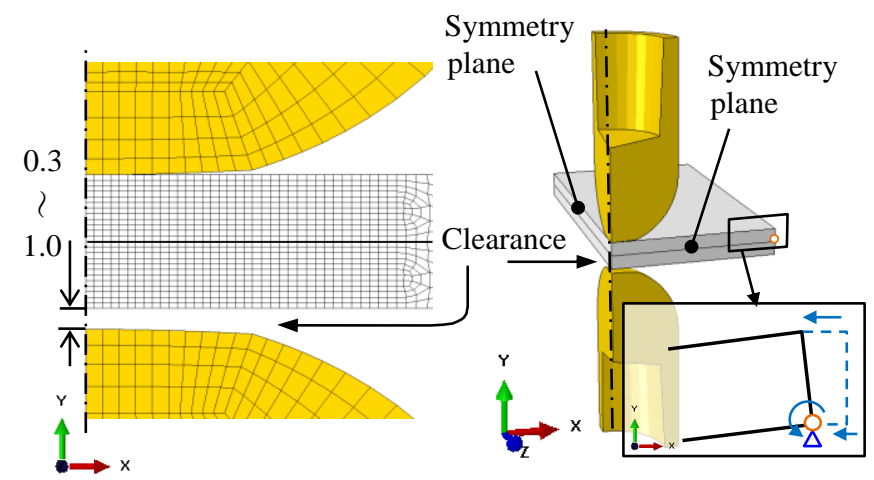

(b) Steel sheet combination with clearance.

Fig. 10 FE analytic model of a spot weld.

\subsection{Evaluation of stress distribution during the cooling process}

Figure 11 shows radial stress distributions during the cooling process. These are stress distributions at each step of completion of electrode-contact cooling, release of the electrodes (start of air cooling), and completion of air cooling for each sheet combination. The stresses were evaluated in the radial direction of the nugget (x-axis direction), which could cause LME cracking. In all cases, corona bonds had been formed at the completion of electrode contact cooling. Tensile stress was generated on the lower-sheet side of the corona bonds due to the influence of spring back when the electrodes were released in the sheet combinations with clearance. The stresses at the completion of air cooling showed a tendency to increase with the size of the clearance.

\subsection{Evaluation of stress and plastic strain in corona bonds}

To elucidate the mechanism driving the initiation of internal cracks in corona bonds, we evaluated the transitions of stress and plastic strain from cooling by electrode-hold contact to electrode release and air cooling. Figure 12 shows transitions of radial stress for four cases. The transition of stress in the radial direction of the nuggets (x-axis direction) in the cooling process is plotted with the horizontal axis as temperature and the vertical axis as stress. The dashed line shows the stress transition in cooling by electrode-hold contact, and the solid line shows the stress transition in air cooling (after electrode release). The evaluation site was a continuous node in the corona bond, and the average value was taken. During cooling by electrode-hold contact, 
Vol.11, No.3(2020)

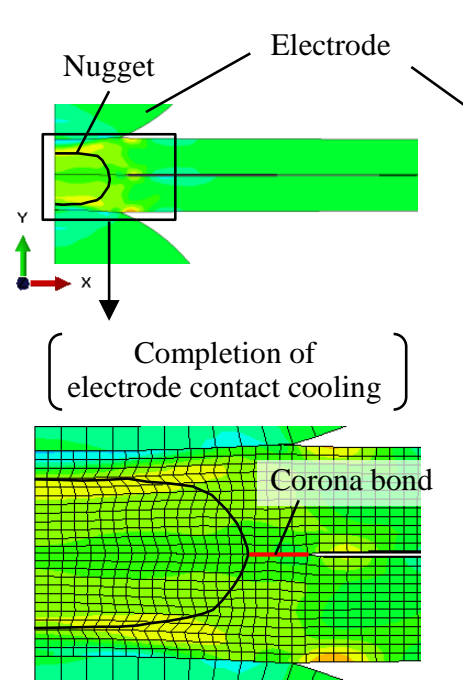

(Release of electrode)

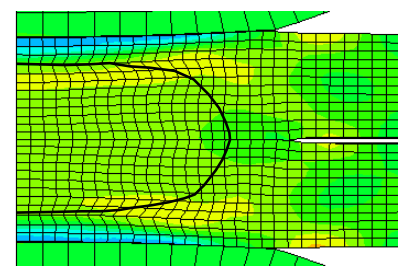

(Completion of air cooling)

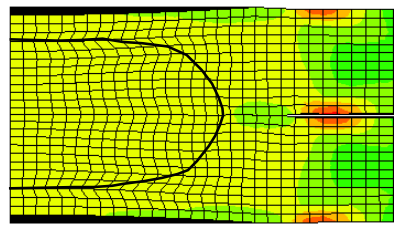

(a) $\mathrm{CL}=0.0 \mathrm{~mm}$

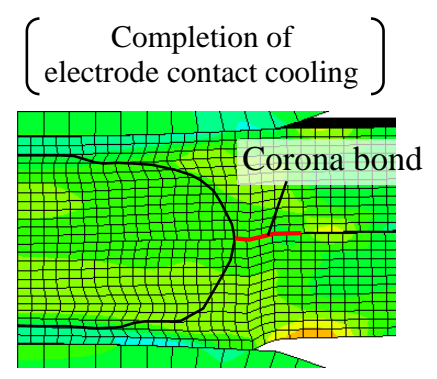

(Release of electrode)
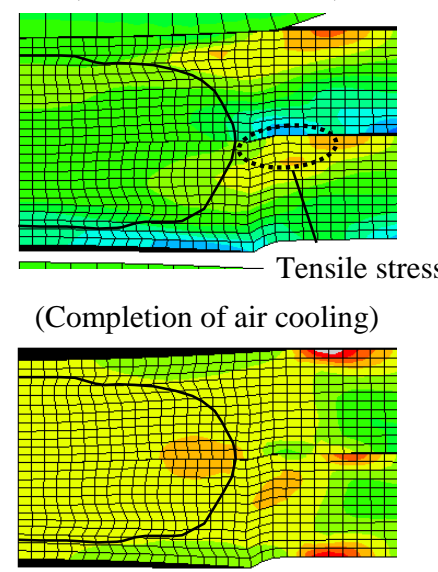

(c) $\mathrm{CL}=0.5 \mathrm{~mm}$
$-600 \quad(\mathrm{MPa}) \quad 600$

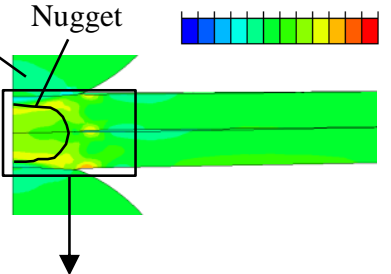

$\left.\begin{array}{l}\text { Completion of } \\ \text { trode contact cooling }\end{array}\right)$

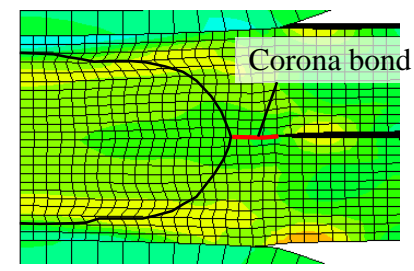

(Release of electrode)

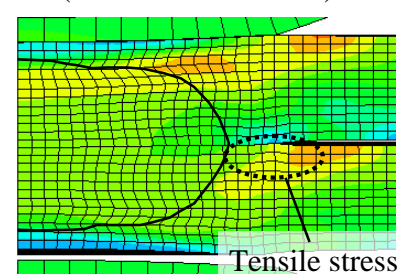

(Completion of air cooling)

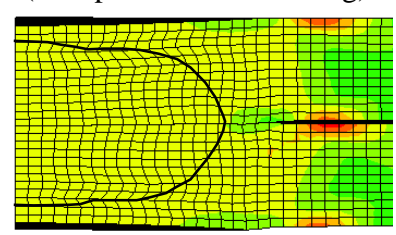

(b) $\mathrm{CL}=0.3 \mathrm{~mm}$
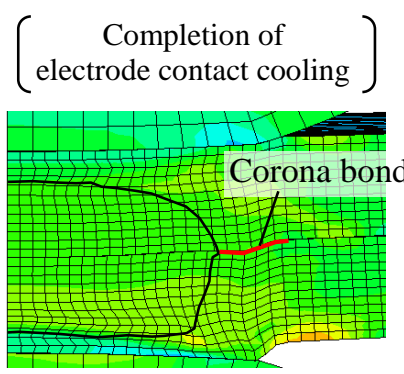

(Release of electrode)

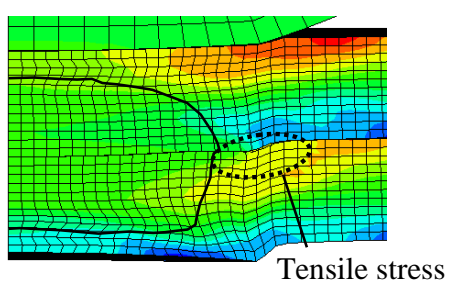

(Completion of air cooling)

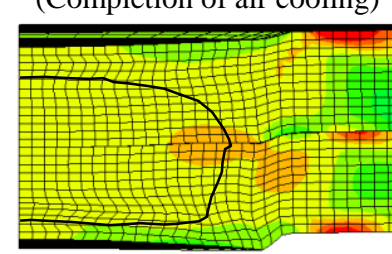

(d) $\mathrm{CL}=1.0 \mathrm{~mm}$

Fig. 11 Radial stress distribution during the cooling process.

stresses were in the compressive direction, but when the electrode was released, stresses increased due to the effect of spring back and turned to the tensile direction when air cooling started. In the case where the clearance was set, the increment was large. Table 1 shows a comparison of stress increments. The maximum stress increment was $\mathrm{CL}=0.3 \mathrm{~mm}$, then $\mathrm{CL}=0.5 \mathrm{~mm}$, and both were around $800^{\circ} \mathrm{C}$ where zinc is molten, which corresponded to the LME cracking in the spot welding experimental results.

Next, we evaluated plastic strains in the nugget radial direction (x-axis direction) during the cooling process. Figure 13 shows radial plastic strain distributions at completion of cooling by electrode-hold contact. In the case of CL $=0.3 \mathrm{~mm}$ and $\mathrm{CL}=$ $0.5 \mathrm{~mm}$, tensile strain could be confirmed in corona bonds while in the case of $\mathrm{CL}=1.0 \mathrm{~mm}$, the deformation of the corona bond was large and compressive strain could be confirmed. Figure 14 shows transitions of plastic strain during the cooling process, and Table 2 shows a comparison of radial plastic strain at the completion of air cooling. During the cooling process, compressive strain occurred in the sheet combinations with $\mathrm{CL}=$ $0.0 \mathrm{~mm}$ (no clearance) and $\mathrm{CL}=1.0 \mathrm{~mm}$, while tensile strain occurred in the sheet combinations with $\mathrm{CL}=0.3 \mathrm{~mm}$ and $\mathrm{CL}=$ $0.5 \mathrm{~mm}$. These results suggest that the increase in stress when the electrodes are released and the tensile strain during the cooling process are factors that determine whether cracks initiate in the corona bonds of spot welded zones.

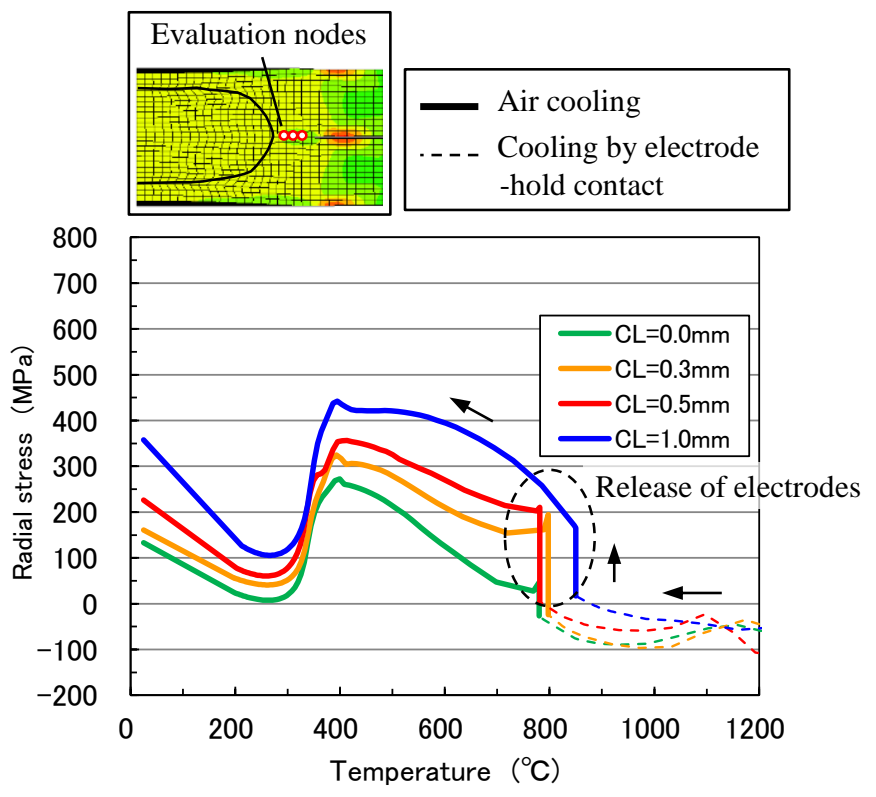

Fig. 12 Transition of stress during the cooling process.

Table 1 Comparison of stress increments.

\begin{tabular}{|r|r|}
\hline $\begin{array}{c}\text { Clearance } \\
(\mathrm{mm})\end{array}$ & $\begin{array}{c}\text { Stress } \\
\text { increment } \\
(\mathrm{MPa})\end{array}$ \\
\hline 0.0 & 73 \\
\hline 0.3 & 218 \\
\hline 0.5 & 206 \\
\hline 1.0 & 148 \\
\hline
\end{tabular}




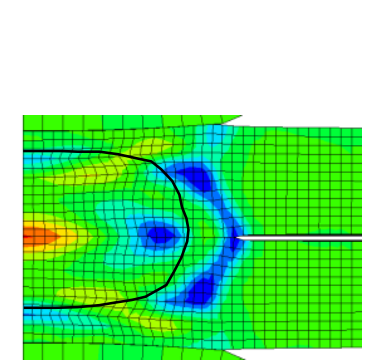

(a) $\mathrm{CL}=0.0 \mathrm{~mm}$

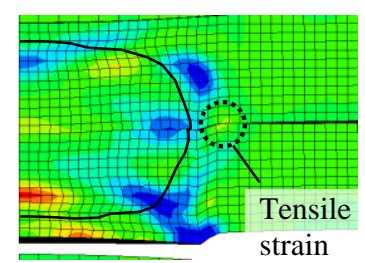

(c) $\mathrm{CL}=0.5 \mathrm{~mm}$

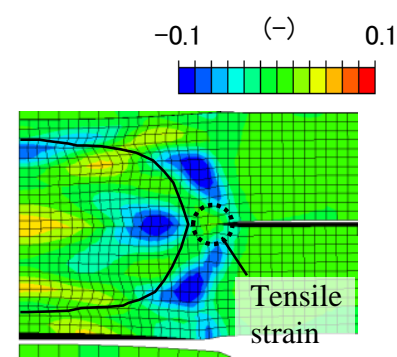

(b) $\mathrm{CL}=0.3 \mathrm{~mm}$

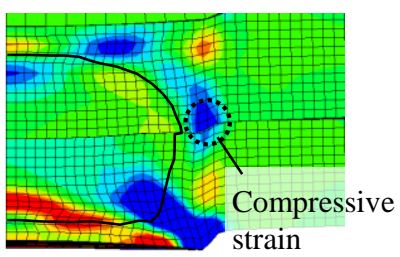

(d) $\mathrm{CL}=1.0 \mathrm{~mm}$

Fig. 13 Radial plastic strain distribution at completion of cooling by electrode-hold contact.

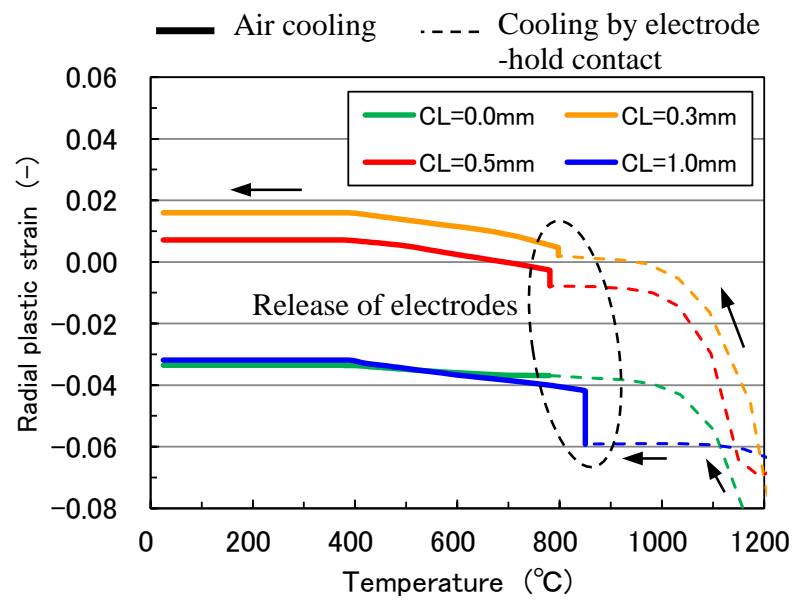

Fig. 14 Transition of plastic strain during the cooling process.

Table 2 Comparison of radial plastic strain at the completion of cooling.

\begin{tabular}{|r|r|}
\hline Clearance $(\mathrm{mm})$ & Plastic strain $(-)$ \\
\hline 0.0 & -0.0336 \\
\hline 0.3 & 0.0160 \\
\hline 0.5 & 0.0072 \\
\hline 1.0 & -0.0319 \\
\hline
\end{tabular}

\section{Examination of the LME cracking mechanism on the outer surface}

\subsection{Spot welding experiment}

Finally, this chapter discusses LME external cracks that begin on the outer surface of spot welds. Figure 15 shows an example of LME external cracks on the outer surface, which are often observed directly under the electrodes. The images show cross-sections of spot welds with a crack on outer surface. These cracks are caused by disturbances such as clearance or largecurrent conditions that procedure spattering. Therefore, in this chapter, we evaluate the stress transitions on the outer surface by applying the spot welding simulation to the conditions to clearance settings and large current using the analytic model described in Section 3.2.

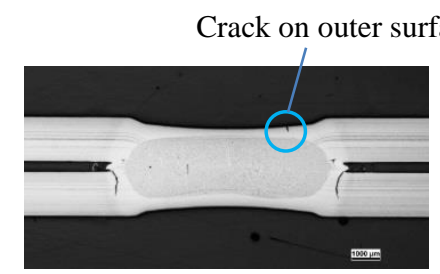

(a) $\mathrm{CL}=0.3 \mathrm{~mm}$
Crack on outer surface

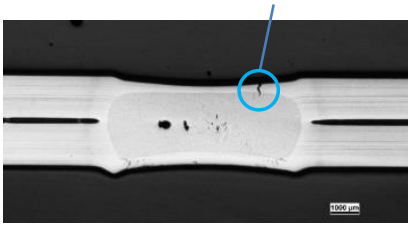

(b) $\mathrm{CL}=0.5 \mathrm{~mm}$
Fig. 15 Cross-sections of spot welds with a crack on the outer surface.

\subsection{Examining the influence of clearance}

Figure 16 shows transition of stress during the spot welding process. The thin solid line shows the stress transition under electric heating, the dashed line indicates the stress transition during cooling by electrode-hold contact, and the solid line denotes the stress transition during air cooling (after electrode release). Since locations of LME cracking on the outer surface change variously, as the representative the evaluation site is a node just below the center of the upper electrode. When cooling by electrode-hold contact began, the temperature dropped rapidly, but the temperature rose again due to heat conduction from the hot interior, and then subsequently dropped again during air cooling after the electrodes were released.

In the case of $\mathrm{CL}=0.0 \mathrm{~mm}$, there was almost no spring back effect of due to release of the electrodes, and the stress turned to the tensile side during air cooling, but was in the temperature range where it is difficult to melt zinc. In the case of $\mathrm{CL}=0.3 \mathrm{~mm}$, the temperature range for generating tensile stress shifted slightly to the high-temperature end. Furthermore, in the case of $\mathrm{CL}=0.5$ $\mathrm{mm}$ and $\mathrm{CL}=1.0 \mathrm{~mm}$, the stress shifted to the tensile side in the temperature range where zinc was molten, and there was a risk of LME cracking.

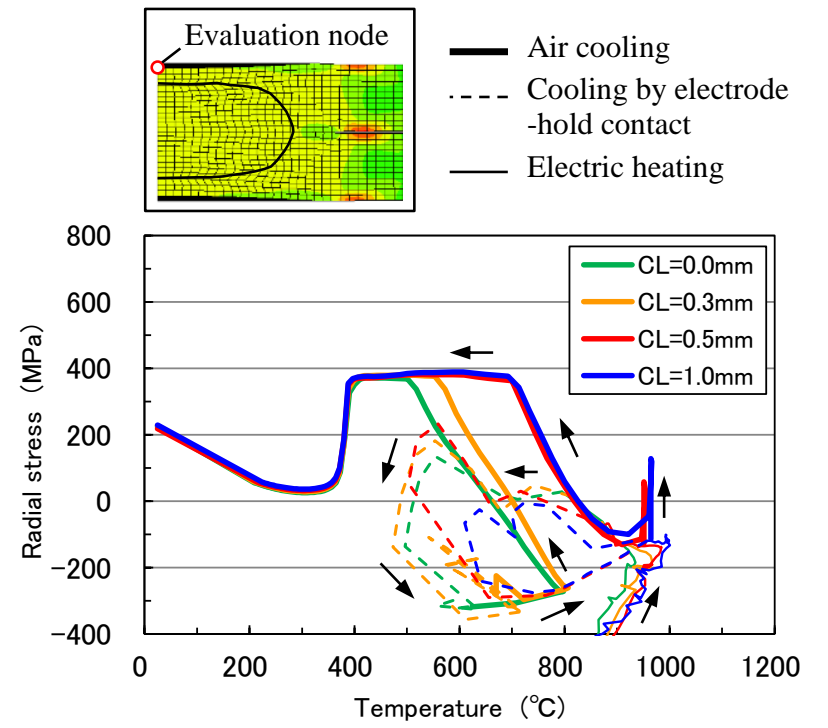

Fig. 16 Transition of stress during the spot welding process.

\subsection{Examining the influence of large-currents}

To study what happens under large-current condition, we performed spot welding simulations on the sheet combination set with $\mathrm{CL}=0.3 \mathrm{~mm}$, applying the conditions of $+1.0 \mathrm{kA}$ and +2.0 $\mathrm{kA}$, based on welding currents for target nugget diameter of 5.0 $\mathrm{mm}$. Figure 17 shows the transition of stress during the spot welding process. 
Vol.11, No.3(2020)

As the current increased, the temperature at the evaluation site (immediately below the center of the upper electrode) rose, the stress transition shifted to the higher-temperature end, and tensile stress occurred in the temperature range where zinc was molten during air cooling.

The results of this chapter indicate that there is a risk of LME cracking on the outer surface just below the electrode under the conditions of setting a clearance and applying a large-current.

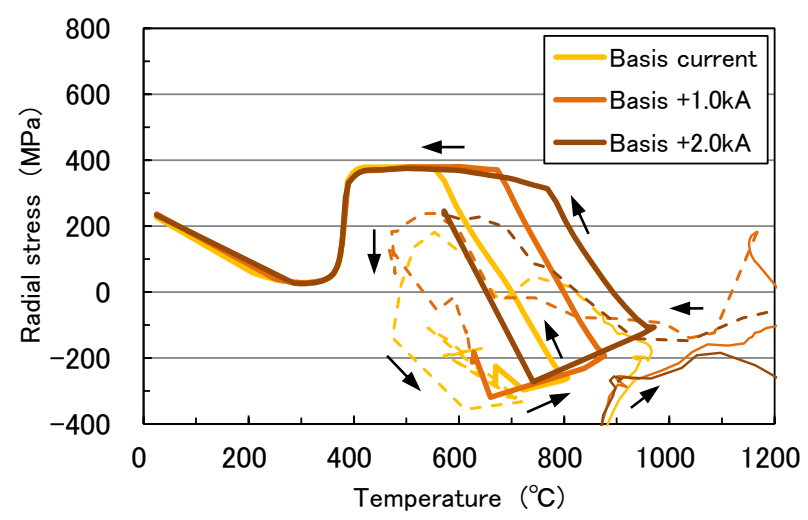

Fig. 17 Transition of stress during the spot welding process. $(\mathrm{CL}=0.3 \mathrm{~mm})$

\section{Conclusion}

In this report, we applied resistance spot welding simulation technology that has been developed based on incrementally coupled electrical-thermal-mechanical fields using finite element analysis to elucidate the LME cracking mechanism. The main results described in this report are summarized below.

(1) We examined the influence of clearance on crack initiation in corona bonds, and found that in the cases of $C L=0.3 \mathrm{~mm}$ and $\mathrm{CL}=0.5 \mathrm{~mm}$, the stress increased due to the spring back effect when the electrodes were released. Plastic strain also increased during cooling, and changed to tensile strain.

(2) We also studied the influences of clearance and large-current conditions on external cracks on the outer surface of spot welds. In both conditions, tensile stress occurred in the temperature range where zinc is molten during cooling.

Based on the above results, the spot welding simulation described in this report is an effective technique for evaluating the stress and plastic strain that cause LME cracking and for studying the mechanism of its initiation. We expect to see this technology used for evaluating the strength of vehicle bodies.

\section{Acknowledgments}

This paper is based on a proceeding presented at the JSAE 2020 Annual Congress (Spring). We would like to thank Mr. Takao Morikawa of Nippon Steel Technology Corporation for his assistance with the numerical simulations.

\section{References}

(1) Fukumoto, M. et al.: SAE paper, 2003-01-2806 (2003)

(2) Fukumoto, M. et al.: 2006 JSAE Annual Congress (Spring) Proceedings. No.74-06, pp.9-12 (2006)

(3) Kikuchi, S. et al.: Preprints of the National Meeting of JWS. No.86, pp.87-88 (2010)
(4) Ueda, H. et al.: Journal of Society of Automotive Engineers of Japan. Vol.50, No.5, pp.1475-1480 (2019)

(5) Li, M.V. et al.: Metall. Mater. Trans. 29B, p661 (1998)

(6) Koistinen, D.P. et al.: Acta Metall. Vol.7, p59 (1959) 